\title{
Corrigendum: Performance Improvement for Detecting Brain Function Using fNIRS: A Multi-Distance Probe Configuration With PPL Method
}

\author{
Xinrui Chen ${ }^{1 \dagger}$, Xizi Song ${ }^{1 \dagger}$, Long Chen ${ }^{1}$, Xingwei $A n^{1}$ and Dong Ming ${ }^{1,2 *}$ \\ ${ }^{1}$ Academy of Medical Engineering and Translation Medicine, Tianjin University, Tianjin, China, ${ }^{2}$ College of Precision \\ Instruments and Optoelectronics Engineering, Tianjin University, Tianjin, China
}

Keywords: functional near-infrared spectroscopy, multi-distance probe configuration, modified Beer-Lambert law with partial path length, activation map, classification

OPEN ACCESS

Approved by:

Frontiers Editorial Office,

Frontiers Media SA, Switzerland

${ }^{*}$ Correspondence:

Dong Ming

richardming@tju.edu.cn

tThese authors have contributed equally to this work and share first authorship

Specialty section:

This article was submitted to Brain Imaging and Stimulation, a section of the journal

Frontiers in Human Neuroscience

Received: 30 September 2021

Accepted: 12 October 2021

Published: 04 November 2021

Citation:

Chen X, Song X, Chen L, An X and

Ming D (2021) Corrigendum:

Performance Improvement for Detecting Brain Function Using fNIRS:

A Multi-Distance Probe Configuration With PPL Method.

Front. Hum. Neurosci. 15:786352.

doi: 10.3389/fnhum.2021.786352

\section{A Corrigendum on}

Performance Improvement for Detecting Brain Function Using fNIRS: A Multi-Distance Probe Configuration With PPL Method

by Song, X., Chen, X., Chen, L., An, X., and Ming, D. (2020). Front. Hum. Neurosci. 14:569508. doi: $10.3389 /$ fnhum.2020.569508

Xinrui Chen was not included as a first author in the published article. Xinrui Chen and Xizi Song now share first authorship. The corrected Author Contributions Statement appears below.

\section{AUTHOR CONTRIBUTIONS}

$\mathrm{XC}$ conceived, designed and performed the experiment, and wrote the manuscript. XS, LC, and $\mathrm{XA}$ supervised the experiment. XC and XS analyzed the data and are responsible for data curation. XS revised the manuscript. XS and DM were responsible for project administration. DM provided resources. All authors approved the final manuscript.

The authors apologize for this error and state that this does not change the scientific conclusions of the article in any way. The original article has been updated.

Publisher's Note: All claims expressed in this article are solely those of the authors and do not necessarily represent those of their affiliated organizations, or those of the publisher, the editors and the reviewers. Any product that may be evaluated in this article, or claim that may be made by its manufacturer, is not guaranteed or endorsed by the publisher.

Copyright () 2021 Chen, Song, Chen, An and Ming. This is an open-access article distributed under the terms of the Creative Commons Attribution License (CC BY). The use, distribution or reproduction in other forums is permitted, provided the original author(s) and the copyright owner(s) are credited and that the original publication in this journal is cited, in accordance with accepted academic practice. No use, distribution or reproduction is permitted which does not comply with these terms. 